\title{
Nuclear Pleomorphism
}

National Cancer Institute

\section{Source}

National Cancer Institute. Nuclear Pleomorphism. NCI Thesaurus. Code C38721.

Having nuclei with various distinct forms. 